\title{
Annual crustal deformation based on GNSS observations between 1996 and 2016
}

\author{
Kamil Maciuk ${ }^{1}$ [D $\cdot$ Stanisław Szombara ${ }^{1}$ \\ Received: 29 September 2018 / Accepted: 22 October 2018 / Published online: 6 November 2018 \\ (C) The Author(s) 2018
}

\begin{abstract}
The article examines the quality of reprocessed GNSS data for determination of seasonal effect in a coordinates' time series. The authors are looking for long-term changes of NEU components on the basis of weekly EPN solutions from the years 1996-2016. This is one of the first such in-depth studies using such a long time period and a large number of stations. Amplitude and its RMS values of fitting function are analysed. The analysis shows that there are significant repeatable coordinate variations: $4.7 \mathrm{~mm}$, $2.9 \mathrm{~mm}$ and $8.3 \mathrm{~mm}$ for the $\mathrm{dN}, \mathrm{dE}$ and dU components, respectively. The research also shows a group of coordinates' time series with very small RMS values below the coordinates' accuracy ( $1 \mathrm{~mm}$ for horizontal, $3 \mathrm{~mm}$ for vertical components), leading to a very good function fitting with relatively small amplitude magnitudes. The authors did not remark any connection with the above described phenomena and geographical location or type of setting up of a base station.
\end{abstract}

Keywords Seasonal variation · Time series · GPS · GNSS · Crustal deformation

\section{Introduction}

A growing number of permanent GNSS (global navigation satellite system) reference stations are excellent research tools for various geodetic and geodynamic areas. In the last 20-25 years, GPS (global positioning system) has been frequently used in various studies both as a main tool and as a support tool for conventional surveying methods. To date, satellite techniques are equated with the term 'GPS'; currently, the term 'GNSS' is more appropriate due to the availability of three additional GNSS systems: the Russian global navigation satellite system (GLONASS), the European Galileo and the Chinese BeiDou. The main research with GNSS solutions' usage is earthquake effects (Levin et al. 2010; Rogozhin 2011; Zhang et al. 2014), crustal deformations (Cho and Kuwahara 2013; Bhu et al. 2014; Trofimenko and Bykov 2014; Bellone et al. 2016), tectonic plate activity (Hammond 2005; Uzel et al. 2013), velocity estimation

Kamil Maciuk

maciuk@agh.edu.pl

Stanisław Szombara

szombara@agh.edu.pl

1 Department of Integrated Geodesy and Cartography, AGH University of Science and Technology, Al. Mickiewicza 30, 30-059 Krakow, Poland
(Kulachi 2000; Pospíšil et al. 2012), water vapour (Priego et al. 2016), volcanic activity (Miller et al. 2003; Caliro et al. 2004) and landslides (Kadirov et al. 2014; Komac et al. 2015; Capilla et al. 2016). The availability of a large number of permanent GNSS stations - such as the IGS (International GNSS Service), EPN (EUREF Permanent GNSS Network) and many other local network satellite solutions - increases the accuracy of classical geodetic techniques such as tachometry or levelling in relation to reducing cost and measurement results. The GNSS technique can detect tectonic movements on a regional scale by establishing a network characterised by a high spatial resolution of ca. $>$ $100 \mathrm{~km}$, but in spite of this, it is still difficult to monitor local or irregular deformations associated with local tensions' accumulation (Tanaka et al. 1998). Using the GNSS techniques that are able to determine seasonal ground motions with accuracy allows for completing 1-2-mm/year movements (Wang et al. 2014, 2015). In this study, the authors included the long-term weekly EPN reprocessing data of an entire network between 1997 and 2016 (834-1890 GPS weeks) for the detection and determination of annual periodical changes of the stations' NEU components.

To date, seasonal crustal deformation detection on the basis of permanent GNSS stations has been conducted (e.g. Zhang et al. 2002; Park and Won 2010; Liu et al. 2015; Milyukov et al. 2015; Araszkiewicz and Völksen 2016; Alinia et al. 2017). Annual signals based on GPS observations were looked at by Bogusz and Figurski (2014), in which the observations from 129 permanent GPS stations from 5 consecutive years were analysed. The 
authors determined the amplitudes and phases of the selected GPS stations, the result being that the amplitudes of a bestfitting sinusoid are between up to $4.1 \mathrm{~mm}$ for horizontal and $4.0 \mathrm{~mm}$ for vertical components, with no evenly distributed phase shifts over the distributed area. Moreover, hydrological and atmospheric influences concentrated over the winter (JanuaryFebruary) and summertime (June-July) were discovered. A similar analysis concerning 30 GPS stations located in Central Europe, based on the daily network solutions over 2 years' intervals, was conducted by Hefty et al. (2005). The results showed very complex behaviour; besides that of individual-for-station linear drifts, seasonal variations as a majority were also observed. The authors detected 1-2-mm station position systematic changes both in a horizontal position and height.

A similar trend was also observed in a group of stations; however, some stations clearly indicated individual behaviour. Bogusz and Figurski (2012) investigated the existence of diurnal and subdiurnal oscillations on the basis of 130 reference stations with a 3-h observation window. The results showed significant variations in an up direction (11 mm), and 4-5 times smaller horizontal variations. A similar analysis is also presented in the work of Araszkiewicz et al. (2009), where 1-h and 4-h observations were used for the investigation of long-term (diurnal, semidiurnal) oscillations. In this work, 70 EPN stations were analysed; only $50 \%$ of the analysed sites' oscillations in the height component and only several percent in the horizontal were observed. The authors also noted that the height component's amplitude is greater than the horizontal component's amplitude. Similar results were achieved by Medvedev et al. (2013), who analysed the Baltic Sea gauge stations. They demonstrated that in most parts of the sea, the types of tides are diurnal or mixed-diurnal; only at some stations did mixed semidiurnal tides prevail. In the research of Hefty et al. (2009), the authors deal with 9 years' worth of observations of 54 points located in the Alpine-Adriatic region and the Balkan Peninsula. The study's main conclusions were that the existence of amplitudes up to $4 \mathrm{~mm}$, but usually $<2 \mathrm{~mm}$, has to be considered as purely local phenomena with no evidence of regional patterns. The supremacy of diurnal oscillations over other periods is also proven by, for example, Kenyeres and Bruyninx (2004), Calais et al. (2006) and Teferle et al. (2007). The existence of oscillations caused by anything other than plate movements' environmental effects is also the result of other phenomena such as thermal (Bogusz et al. 2011), foliage (Park and Won 2010) and snow (Wang et al. 2015) effects.

\section{European Permanent Network}

The network of permanent GNSS reference stations is one of the four space geodetic techniques (DORIS, GNSS, SLR and VLBI) used for the realisation of the ITRS (International Terrestrial Reference System). EUREF is the IAG (International Association of Geodesy) Regional Reference
Frame Sub-Commission for Europe. It was created to define, provide access to and maintain a standard coordinate system throughout Europe-ETRS89 (European Terrestrial Reference System 1989). EUREF consists of $321^{1}$ stations (97 of them also belong to the IGS, Fig. 1), a Central Bureau and a few of analysis centres (Bruyninx 2000).

In 1996, the EPN was created, based on a partnership of GNSS site operators who are willing to share their data, products and public services. Currently, more than 100 European agencies/universities are involved in the EPN (Bruyninx et al. 2012), and they operate in a network under defined standards and guidelines that guarantee the long-term stability of the EPN's products. In order to optimise EPN data processing, the network is divided into subnetworks that are separately processed by 16 EPN Analysis Centres (AC). The main products of the EPN are weekly combined sites' positions published in SINEX (Solution INdependent EXchange Format), daily combined site zenith path delays, cumulative site positions and velocities (both in ITRS and ETRS - European Terrestrial Reference System) and residual position time series.

Due to inconsistent date usage and ACs' solution strategies, the results are incompatible. This was a consequence of the EPN solutions used that were strongly dependent on the product. Due to this, the idea arose of the creation of a homogeneous coordinates' time series of ETRF definition based on whole network elaboration by the use of archive data and new models and strategy. Reprocessing was an EPN project set up in 2009 to assure much better quality and homogeneity of products (http://www.epncb.oma.be/_productsservices/ analysiscentres/repro1.php). Henceforth, inconsistency between the consecutive solutions and frame realisations is transferred by the applied products. Reprocessing of a regional network became possible due to the availability of reprocessed orbit and clock products (Steigenberger et al. 2006). There are also defined standards such as the application of absolute PCV, defined mapping functions, consistent datum realisation and SINEX as a solution standard (EPNCG 2016).

\section{Mathematical model}

An investigation of seasonal positions' time series changes has not been performed widely for the following reasons. The number of permanent stations rapidly started to grow at the beginning of the twenty-first century and access has been difficult due to the lack of widely available sources such as ftp servers. Moreover, over the years, the accuracy of available data has been growing. In addition, reference frame changes, low precise product quality (provided for example by IGS), and upgrade of solution strategy and software changes caused

\footnotetext{
${ }^{1}$ http://www.epncb.oma.be/_networkdata/stationlist.php (access 29-082017).
} 
Fig. 1 EPN tracking network (http://www.epncb.oma.be/ networkdata/stationmaps.php, 25-08-2017)

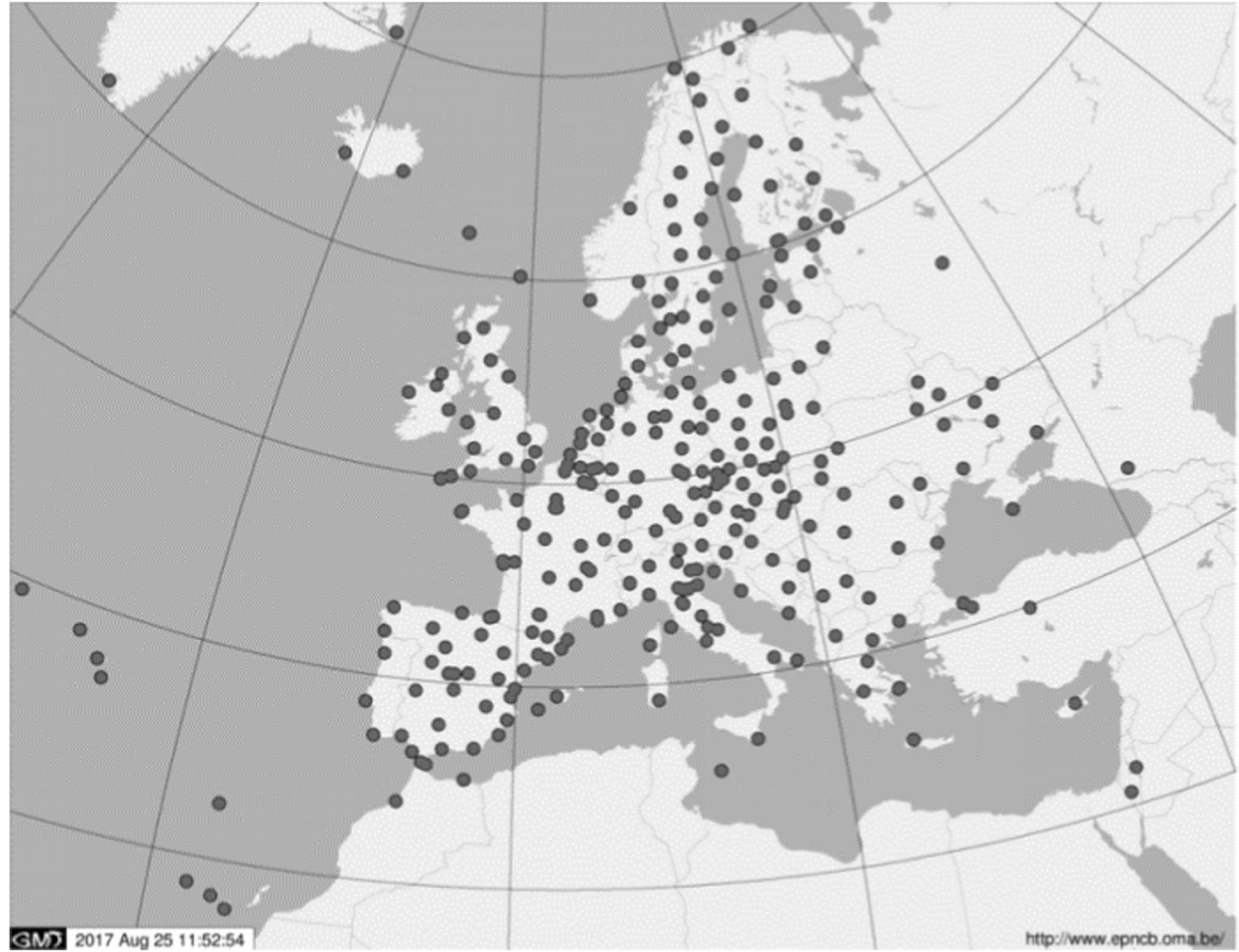

inconsistency with respective solution over the years. A remedy to the aforementioned problems is reprocessed data based on homogenous solutions. A second EPN network reprocessing campaign (repro2) covered all the stations which are operating in the network from January 1996 to December 2014 based on one coherent strategy using current capabilities (http://www. epncb.oma.be/ productsservices/analysiscentres/repro2.php). Repro2 helps in a more correct way to compare and analyse processed data with the elimination of all biases connected with software, algorithms or the process strategy. Discontinuities and outliers are removed from the geocentric coordinates' time series and, according to relevant EPN velocities vectors (Fig. 2 ), each component $C_{k}\left(t_{i}\right)$ at epoch $t_{i}$ is converted based on epoch $t_{0}$ using the equation (Hefty et al. 2005).

$C_{k}\left(t_{i}\right)=C_{k}\left(t_{0}\right)+v_{C k} \cdot\left(t_{i}-t_{0}\right)$

where $C=X, Y, Z$ ECEF (Earth-centred Earth-fixed) components, $C_{k}\left(t_{0}\right)$ is the station's position at the epoch $t_{0}$ for the respective station, and $v_{C k}$ is the velocity of the $k$ component. The solutions are generated week by week, and subsequently the positions are converted into NEU (north, east, up) components with respect to the mean of all available epochs for each station's $i$ according to Eq. (2):

$$
\left[\begin{array}{l}
d N_{i} \\
d E_{i} \\
d U_{i}
\end{array}\right]=\left[\begin{array}{ccc}
-\sin \varphi_{i} \cos \lambda_{i} & -\sin \varphi_{i} \sin \lambda_{i} & \cos \varphi_{i} \\
-\sin \lambda_{i} & \cos \lambda_{i} & 0 \\
\cos \varphi_{i} \cos \lambda_{i} & \cos \varphi_{i} \sin \lambda_{i} & \sin \varphi_{i}
\end{array}\right]\left[\begin{array}{l}
d X_{i} \\
d Y_{i} \\
d Z_{i}
\end{array}\right]
$$

The raw $\mathrm{XYZ}$ coordinates are in the IGb08 reference frame with outliers and discontinuities (top left), XYZ coordinates without discontinuities and outliers (top right), accommodated station velocities (bottom left) and transformation into final NEU local Cartesian coordinates (bottom right) according to Eq. (2). The data analysis taken into considerations consists of 321 European permanent GNSS stations, including active and former (inactive on March 2016) stations. These are analysed weekly and the final results are in a SINEX format between 834 and 1890 GPS weeks (January 1996-March 2016, Fig. 3).

For proper seasonal variation estimation, a criterion of a minimum 4-year interval of data with $90 \%$ coverage at least $(>180$ results per station) is used. Taking into consideration this criterion, 237 GNSS stations are left for further analysis. The authors are looking for seasonal and annual coordinates' changes so into each component four parameters of Eq. (3) are determined:

$k\left(t_{i}\right)=a_{k}+b_{k}\left(t_{i}\right)+c_{k} \sin \left(\omega t_{i}+d_{k}\right)$

where $k=N, E$ and $U$ components at $i$ epoch, $\omega=2 \pi \frac{\mathrm{rad}}{\text { year }}, a_{k}, b_{k}$, $c_{k}$ and $d_{k}$ are the estimated parameters of the $k$ component, $a_{x}$ and $b_{x}$ are the linear parts, $c_{x}$ is the amplitude function initial value and $d_{x}$ is an initial phase. This kind of simple sinusoidal function for each NEU component is termed the best-fitting function (Bogusz and Figurski 2014) for these kinds of elaborations. Similar research also confirms that in long-term coordinates' time series analyses, annual periodical changes form the largest part of seasonal, reparative variations (Collilieux et al. 2011; Wang et al. 2015; Bogusz and Klos 2016). Ray et al. (2008) show the 
Fig. 2 Example of east coordinate time series processing
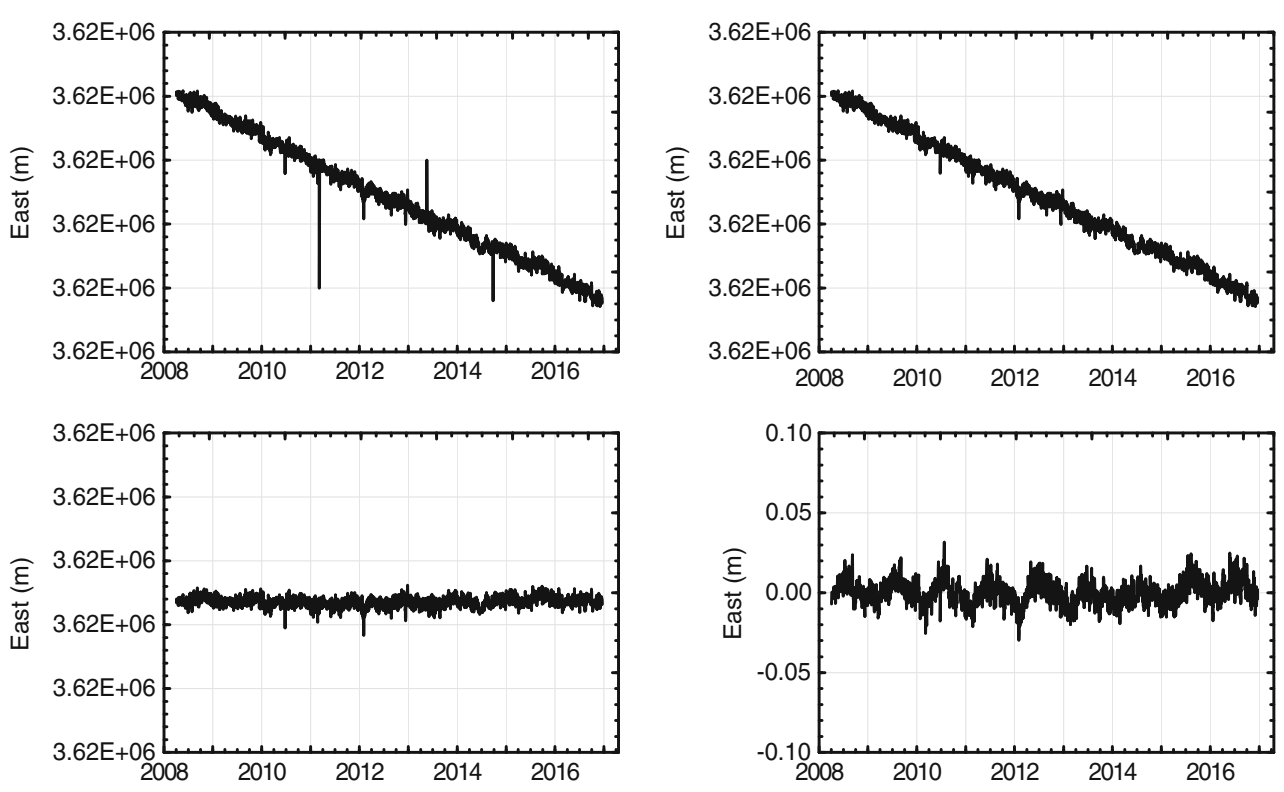

existence of a draconitic year (351.2 days) as well as the existence (Bruyninx et al. 2005) of a tropical year (365.2422 days). A draconitic year is the interval needed for the Sun to return to the same point in space relative to the GPS orbital nodes (as viewed from the Earth) (Ray et al. 2008). In this work-based of the aforementioned research - the authors assume only the existence of a tropical year's oscillations. Linear regression, for example for plate tectonic motion, is the most commonly used in geophysics (Bogusz and Klos 2016). The parameters of the analysed function $k\left(t_{i}\right)$ are determined by unweighted least square method according to the formula (Tan 2018):

$X=\left[A^{T} A\right]^{-1}\left[A^{T} L\right]$

where $X$ is a vector of unknowns $4 \times 1$ (long-term trend components of $k(\mathrm{~N}, \mathrm{E}, \mathrm{U})), L$ is the $237 \times 1$ vector of observations (north, east and up components) and $A$ is the design (observation) matrix $237 \times 4$.

\section{Results}

\section{Seasonal changes}

In general, the potential seasonal variation factors on site positions can be grouped into three categories (Dong et al. 2002). The first category is gravitational excitation, mostly from the Moon and Sun; seasonal polar motion and loading displacements due to Earth, atmospheric and ocean tides can be grouped into this category. A polar tide loading with a spectrum of mostly annual and Chandler wobble also belongs to it. The second category is seasonal variation hydrodynamics with thermal factors. This category also includes seasonal deformations from atmospheric pressure, non-tidal sea surface fluctuations and terrestrial water storage. The third category includes varied errors such as satellite orbit model error, atmospheric models, phase centre variation model and local multipath.
Fig. 3 Length of coordinates' time series for all the analysed stations

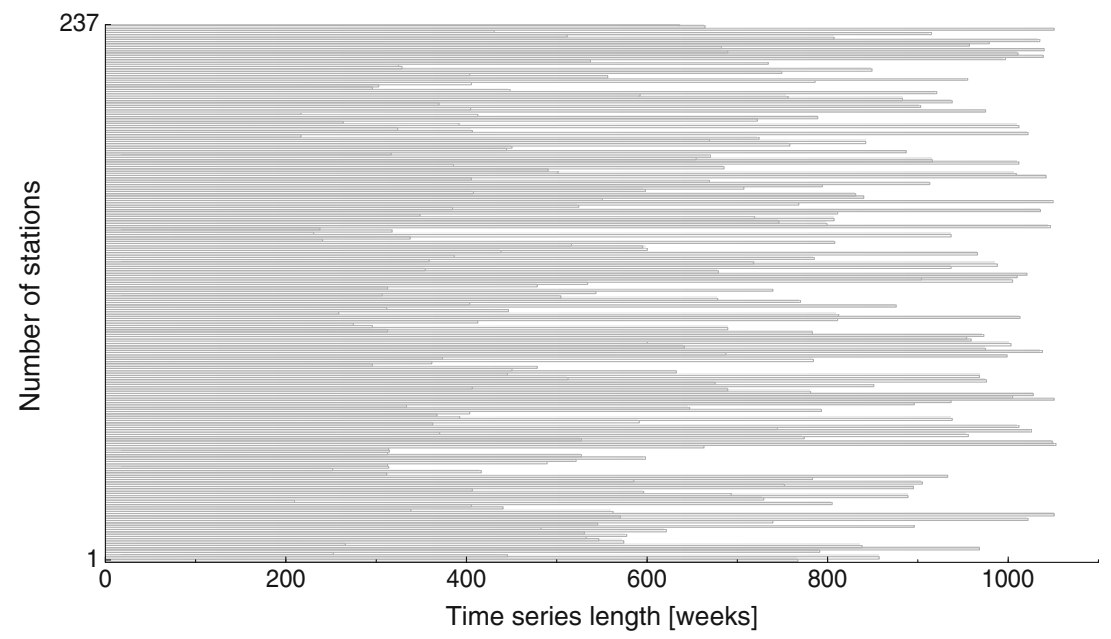


In this work, the authors analysed the annual variations together with the amplitude and phase of the vertical and horizontal NEU components. For the determination of Eq. (3), the parameters are determined by least square method using the MATLAB curve fitting toolbox (MathWorks 2004). Repro2 based on the currently available precise product is the best of today's elaboration tools. Compared to other own elaborations, it is processing with the best minimalizing errors as described in the first and third categories mentioned above. And - due to the usage of cumulative solutions - it is the most accurate elaboration (Araszkiewicz et al. 2010).

In some of the analysed station coordinates' changes, seasonal annual changes can be seen; in others, the amplitude magnitude is lower than the coordinate determination accuracy. Figure 4 presents a coordinates' time series of the three biggest amplitudes for the north, east and up components of all the stations. The blue line with circles is the coordinate time series and the red line - the fitting function. These stations are SMLA ( $\mathrm{dN}$ amplitude is $4.71 \mathrm{~mm} \pm 1.96 \mathrm{~mm}$ RMS [root mean square error]), BOLG (dE $2.85 \pm 1.21 \mathrm{~mm}$ ) and LARM (dU $8.32 \pm$ $4.14 \mathrm{~mm}$ ). It is worth noting that the positions' time series are of a different length so it does not have an influence on amplitude. The BOLG station has the longest coordinates' time series of Fig. 4 (> 577 weeks, $>11$ continuous years). On the other hand, the LARM station ( 259 weeks, almost 5 years) is the shortest coordinates' time series in Fig. 4. An investigation of season and amplitude shows minima/maxima correlation. Figure 4 indicates that minimal (negative) amplitudes (e.g. GPS weeks 1700, 1752 and 1804) occur in August (August 2012, GPS weeks 1699-1703; 2013, 1751-1755 and 2014, GPS weeks 1803-1808). On the other hand, maxima (positive) amplitudes (e.g. GPS weeks 1675, 1727 and 1779) appear mostly in the month of February (February 2012, GPS weeks 1673-1677; 2013, 1725-1729 and 2014, 1777-1781). It shows the subsequent uplift of the ground at the end of the winter. At the end of summer, coordinates' time series amplitude shows the reduction of a station's height. These phenomena are probably connected with underground water or uplift after winter snow melt.

Figure 5 presents the values of amplitudes for each direction ( $>1 \mathrm{~mm} \mathrm{dN}, \mathrm{dE}$ and $>3 \mathrm{~mm} \mathrm{dU}$ ). Only $\sim 20 \%$ of amplitudes of the $\mathrm{dN}$ and $\mathrm{dE}$ coordinates are greater than the coordinate determination error and might be considered reliable. In the case of the up coordinates, this number is around $10 \%$. It can be clearly seen that both horizontal coordinates' amplitudes are 2-3 times smaller than the vertical ones. This could be explained by a couple of factors. First of all, due to the GNSS constellation, the vertical coordinates are determined with a three-time smaller accuracy than the horizontal ones. Moreover, crustal deformations of the vertical components show greater amplitudes (e.g. Milyukov et al. 2015).

The analysis of the horizontal displacement's directions of stations with $>1 \mathrm{~mm}$ amplitude is shown in Fig. 6. During the
Fig. 4 Stations with maximum coordinates' changes
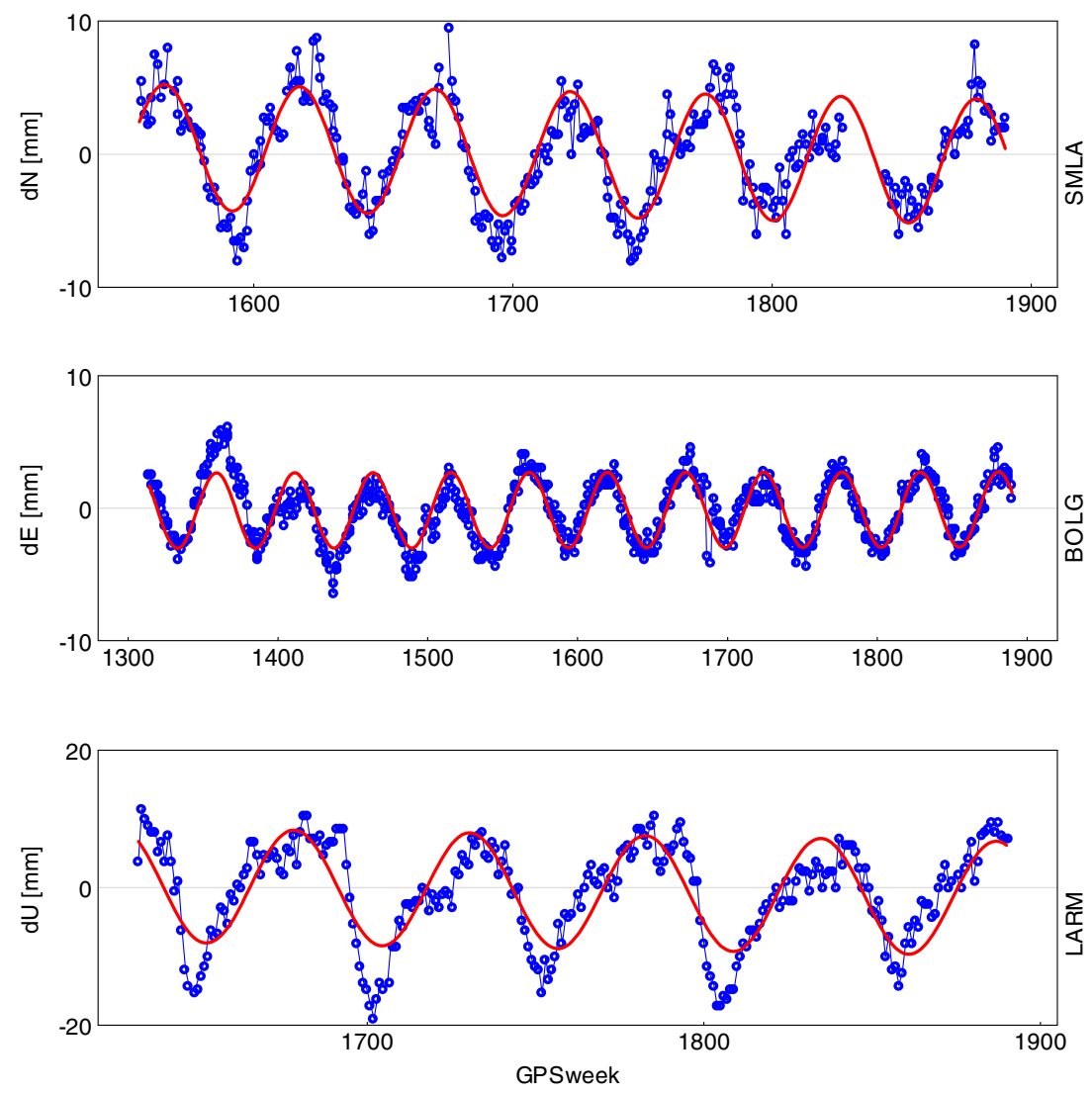

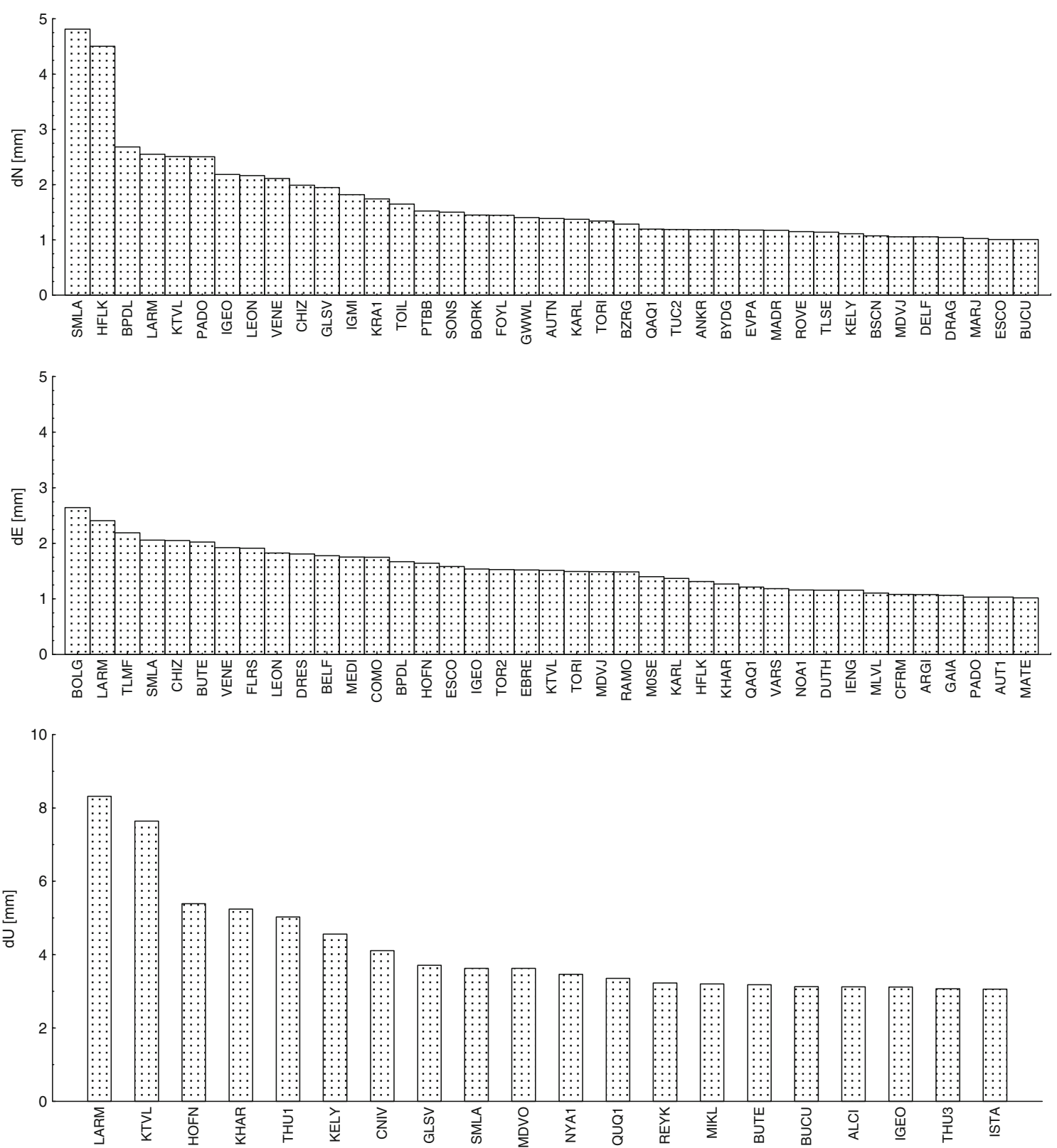

Fig. 5 Graph of the biggest amplitudes for each direction (horizontal $>1 \mathrm{~mm}$, vertical $>3 \mathrm{~mm}$ )

Fig. 6 Averaged displacement directions of the stations with amplitudes $>1 \mathrm{~mm}$. a dN directions. $\mathbf{b} \mathrm{dE}$
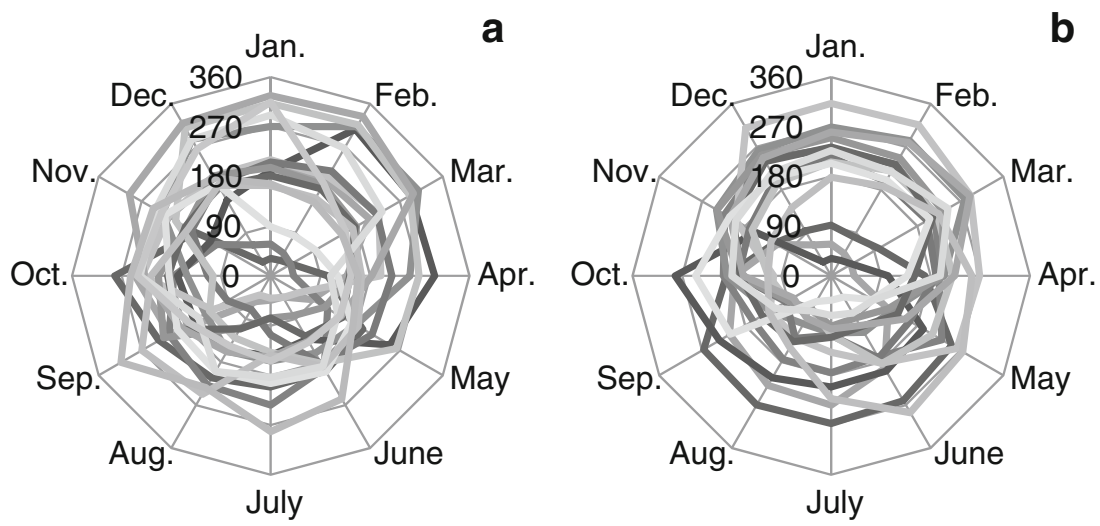
Fig. 7 Stations with minimum RMS of fitting functions
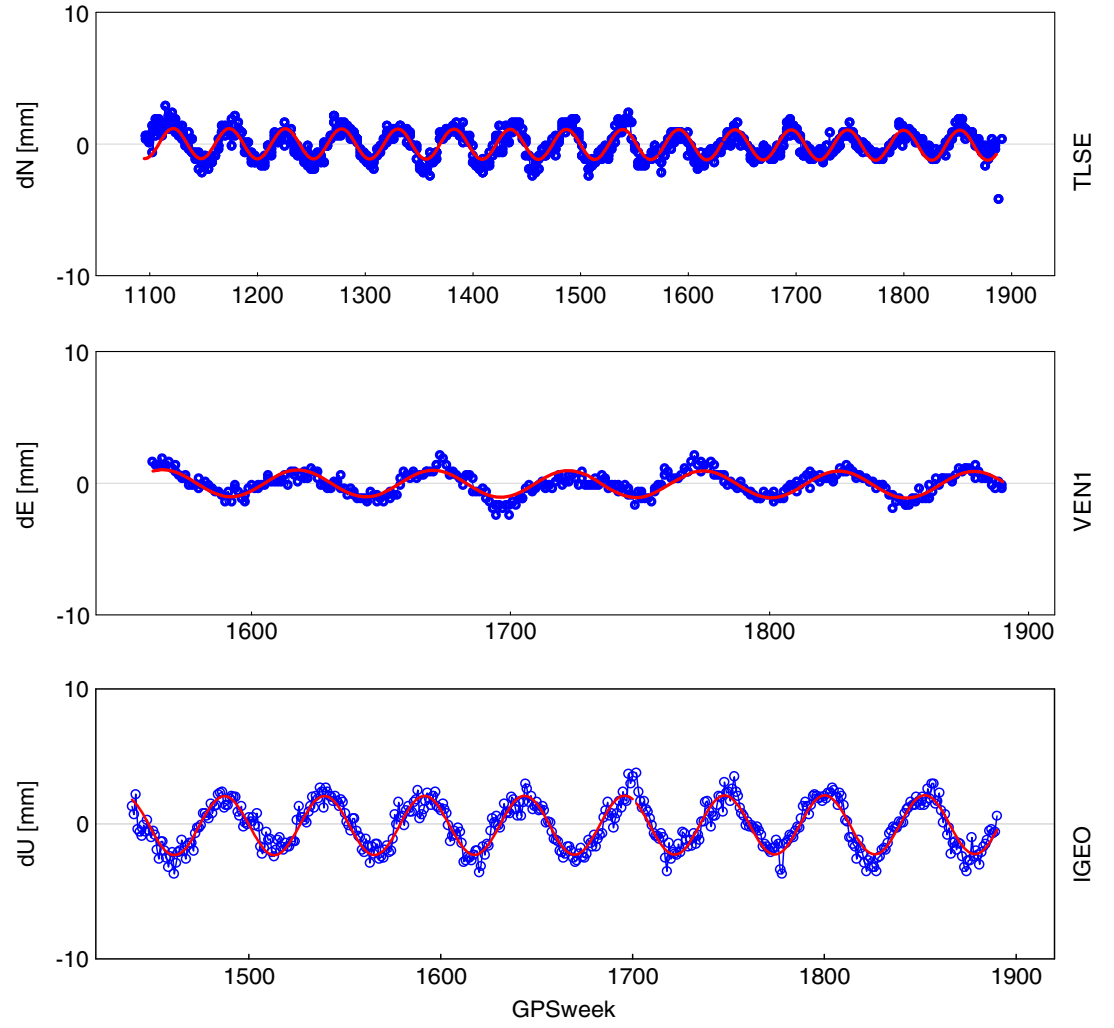

winter months (January to March), in most cases, the displacements have a western/north-western direction, while during the summer months (July to September), they have a south/ south-eastern direction. However, this reliance is more noticeable for the $\mathrm{dE}$ amplitudes.

Investigation of the minimum RMS for each of the directions shows a number of stations with a smaller than horizontal $(<1 \mathrm{~mm})$ and vertical $(<2-3 \mathrm{~mm})$ coordinate determination accuracy. The positions' time series of the station with the smallest RMS for each coordinate is shown in Fig. 7. Contrary to the coordinates' time series presented in Fig. 4, the fitting function is more consistent with the coordinates' time series in Fig. 7, but owing to concerns over accuracy, this function's parameters are unreliable. Figure 7 presents the stations with minimum RMS for each of the directions: TLSE, amplitude $0.61 \mathrm{~mm}$; VEN1, $0.46 \mathrm{~mm}$ and IGEO, $2.60 \mathrm{~mm}$.

Figure 8 shows the dependency between amplitude quantity and RMS of the stations with the smallest RMS $(<3$ mm RMS for the horizontal and $<9 \mathrm{~mm}$ for the vertical coordinate). Figure 8 shows that in a majority of cases, amplitude size is smaller than its determination error for the horizontal coordinates, and in the case of vertical ones - in almost all cases.

The nature of the different annual coordinate amplitude variations is preferably random for at least two reasons. Firstly, there is no geographical dependence on the same size of amplitude of the stations located in the same area. Secondly, seasonal changes and their amplitudes are observed only in one coordinate of each of the analysed stations, so there is no more than one direction of visible trend on the analysed stations.

\section{Near distance stations}

For a better interpretation of the nature and trends of the analysed coordinates' time series, a list of near distance stations with either large amplitudes $(>1 \mathrm{~mm})$ or small RMS values $(<$ $1 \mathrm{~mm}$ ) are created and filtered. The analysis of all the stations between 1996 and 2016 shows a number of pairs of stations located near to each other. Mostly, they are built in research institutes and universities for the studies with near distance pair of stations. During the analysis period, there are also a couple of stations located in the same pillar/base, but due to a number of factors, there is a discontinuity between the working time of one and the other. These factors could be, e.g. destruction of the station (INVE station replaced by INVR, EUREF mail No. 4187), antenna monument alteration (PFAN by PFAN, MANS by MAN2, EUREF mail No. 3772), a new pillar (NOTO by NOT1, EUREF mail No. 0611) or a station renaming (OBER to OBE2, EUREF mail No. 1057). Figure 9 presents examples of the above stations coordinates' pair time series. The MANS station is replaced by MAN2 and the discreteness is $>2$ years long. For the $\mathrm{dN}$ coordinate, MANS and MAN2 amplitudes are 1.00 and $0.88 \mathrm{~mm}$ with 1.04 and $0.74 \mathrm{~mm}$ RMS, respectively. It shows that after a change of the base/monument or 

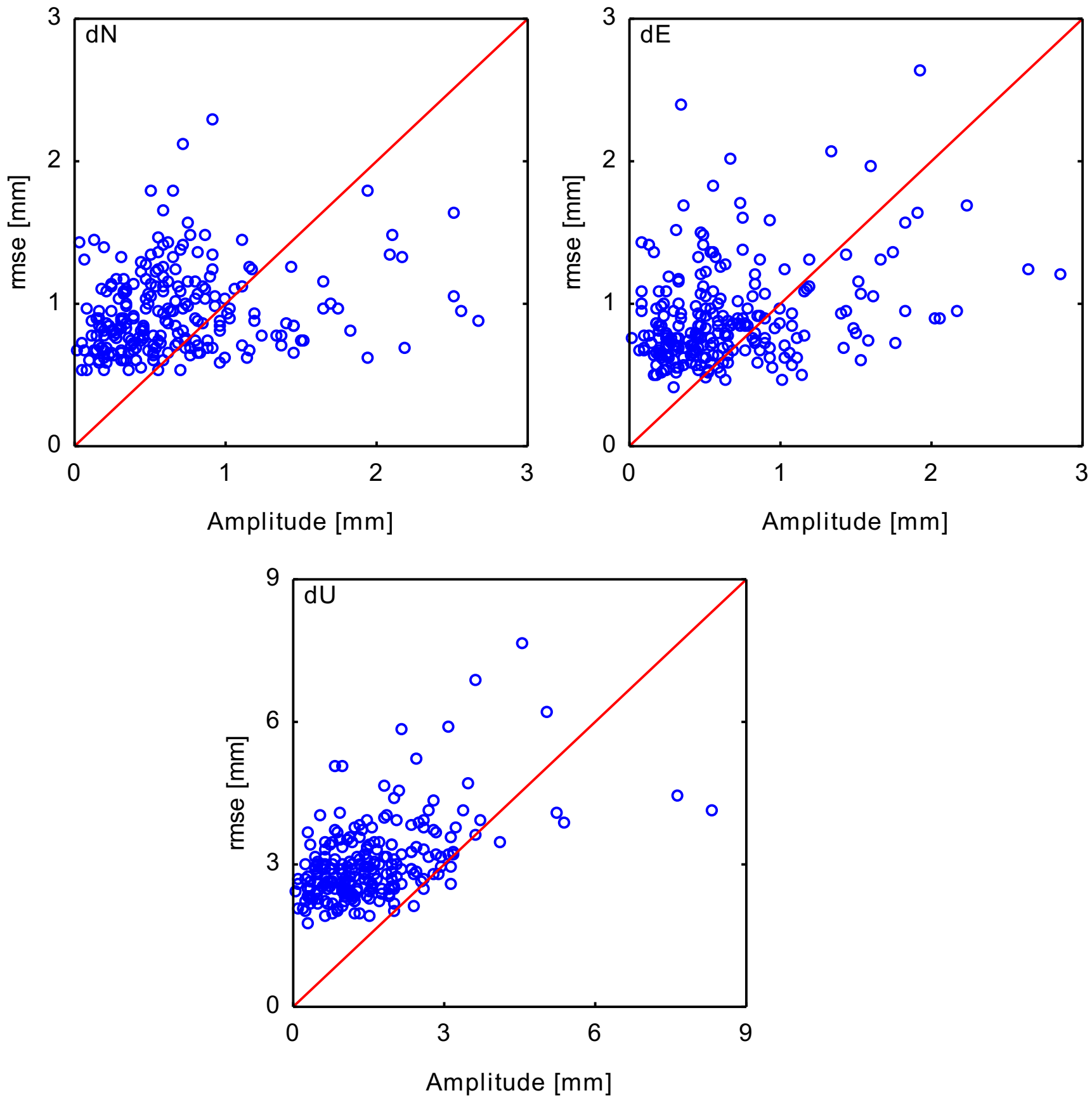

Fig. 8 Amplitudes vs. RMS depending on the line fitted functions

another change, there might be different positions' time series conduct with contrasting RMS.

Figure 10 presents the location of the chosen coordinates' four time series of near distance stations: 1 (KRA1 and KRAW, Krakow, Poland, distance $3.2 \mathrm{~m}$ ), 2 (VENE and BOLG, Venezia and Bologna, Italy, $126 \mathrm{~km}$ ), 3 (MEDI and MSEL, Medicina, Italy, $26 \mathrm{~m}$ ) and 4 (TORI and IENG, Torino, Italy, $5.46 \mathrm{~km}$ ). The graph presents only one direction with the biggest amplitude for each pair.
The pair KRAW-KRA1 is the closest each other's vector $3 \mathrm{~m}$ (Fig. 11). KRA1 has been integrated in the EPN since March 2010. Both stations show similar shift and amplitude, which might be explained by the short distance and distribution on the same building's roof on the concrete pillars. Concerning the pair VENE-BOLG at the distance of $126 \mathrm{~km}$ in the easterly direction, the amplitude degree is similar but the phase is shifted by about half a year $\left(\sim 180^{\circ}\right)$ and shows no correlation. It might be explained by the large distance between these stations and the 
Fig. 9 An example of stations with a break in functioning due to the change of the base

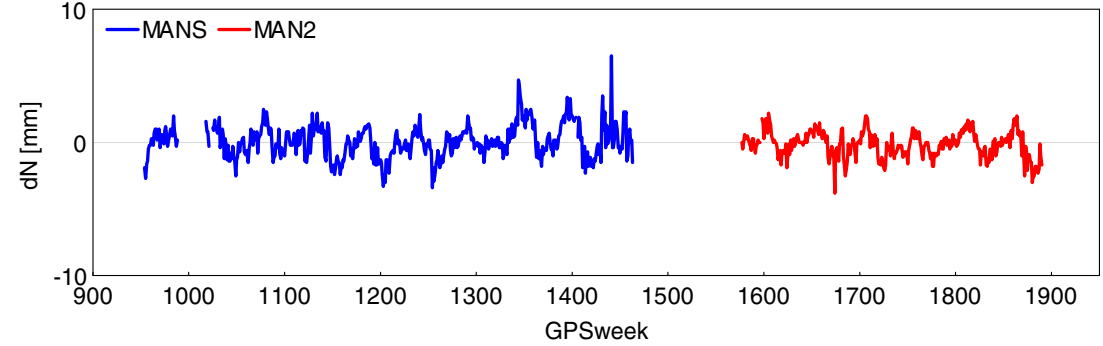

different foundation bases. The pair MEDI-MSEL is a very short 26-m vector distance but with a different ground set: MSEL is on a concrete foundation on a steel pole, while MEDI is on concrete pillar set up on the ground. The more stable is the MEDI station mounting. The MSEL station is fragile due to the carried forward vibrations of a nearby road and the broad platform the station is mounted on. In the case of the TORI and IENG pair of stations, there is visible similarity in the dU time series. The stations are located $\sim 5.5 \mathrm{~km}$ from each other, so almost a similar coordinates' time series route might be explained by the same local tectonic plate movement.

The KRAW and KRA1 stations are located on the top of one of the AGH University of Science and Technology buildings in Krakow, Poland. The former includes into the EPN in 2003, and the latter in 2011; the distance between them is $3.2 \mathrm{~m}$ (Fig. 12).

After the inclusion of KRA1 in 2011, the nature of the coordinates' time series continuation can be clearly seenboth in phase and amplitude magnitude. For a similar, very close distance in the case of the MEDI-MSEL pair of stations
(26 m) and east coordinate, there are also similar amplitude and phase values, but with shifting of the $\pi$ value phase. This might be caused by the different stations' ground mounting.

\section{Discussion and summary}

In this work, a complex analysis of all the EPN stations' coordinate variations between 2006 and 2016 has been made. The obtained data based on weekly, reprocessed solutions are converted into a local Cartesian coordinates NEU. The final coordinates' time series are fit by least square method to a four parameter combination of line and yearly sinusoidal function. The authors analysed the magnitude of functions' amplitude which shows up to a 4.7-mm value for horizontal components and $8.3 \mathrm{~mm}$ for vertical ones. Moreover, annual coordinate variations are noticeable only for a part (237) of all the analysed stations. Only $20 \%$ of horizontal and $10 \%$ of vertical amplitude magnitudes are bigger than their RMS. There is
Fig. 10 Distribution of the presented pairs of stations (http:// www.epncb.oma.be/_ networkdata/stationmaps.php, access 16-08-2017)

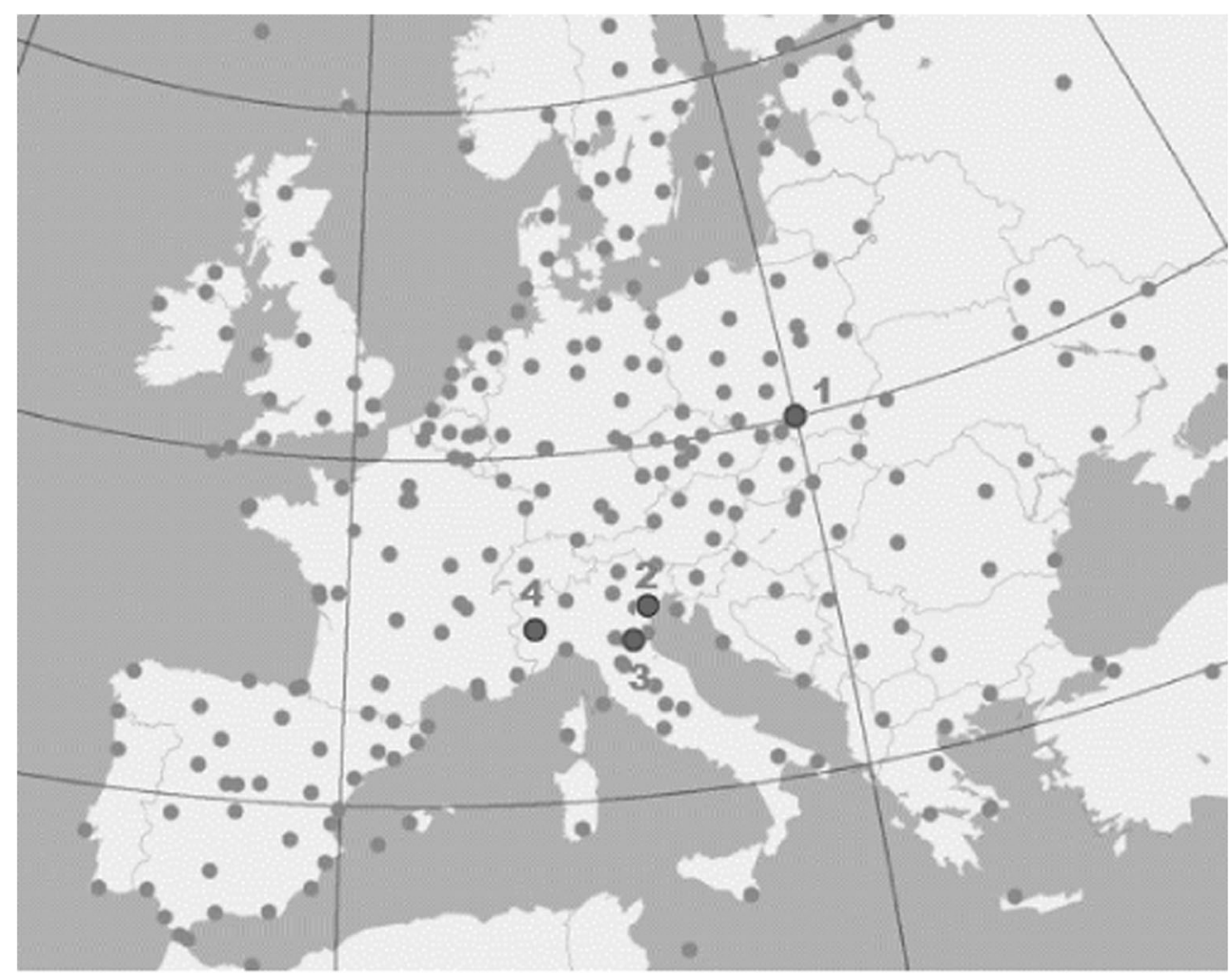


Fig. 11 Graph of the selected pair of stations' coordinate variations
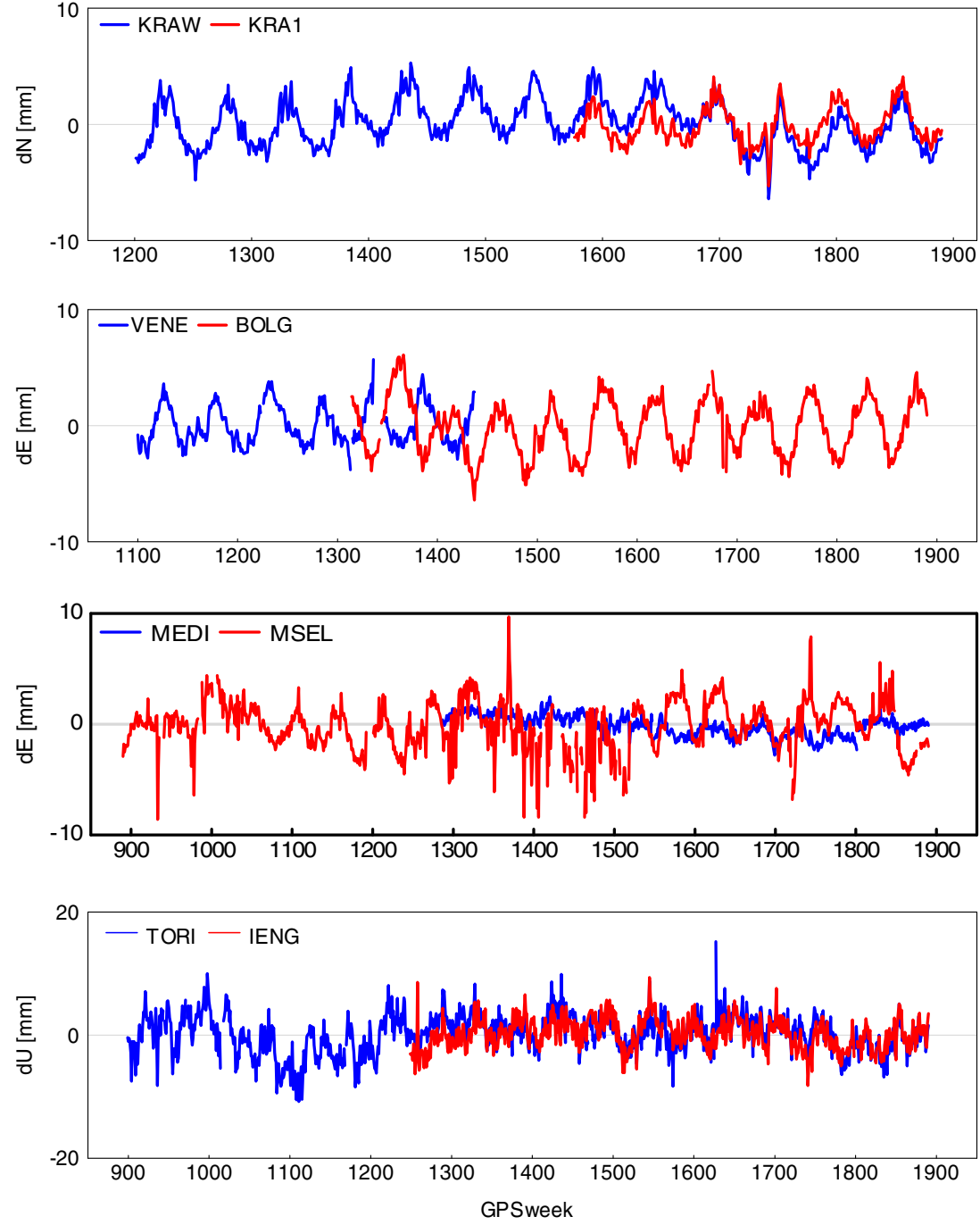

also a group of components' time series with very small RMS errors (connected with a very small function's amplitude) showing $0.6 \mathrm{~mm}$ and $0.5 \mathrm{~mm}$ interpolation error for the $\mathrm{dN}$ and $\mathrm{dE}$ directions, respectively, and $2.6 \mathrm{~mm}$ for the $\mathrm{dU}$ component. The authors also analysed four pairs of near distance stations with at least 4 years' simultaneous working time. There are two extremely short vectors $(5 \mathrm{~m}$ and $26 \mathrm{~m})$ and two medium ones $(5.5 \mathrm{~km}$ and $126 \mathrm{~km})$. The results show that the type of antenna mounting has a great influence on the components' time series course, and similarity in the coordinates' time series pairs decreases with distance. However, it is evidenced that in some regions, there are seasonal, repeatable coordinates' variations that are strictly connected with local tectonic movements and the way of antenna mounting.

Fig. 12 Distribution of the KRA1-KRAW and MEDI-MSEL pairs of stations (http://www. epncb.oma.be, 16-08-2017)
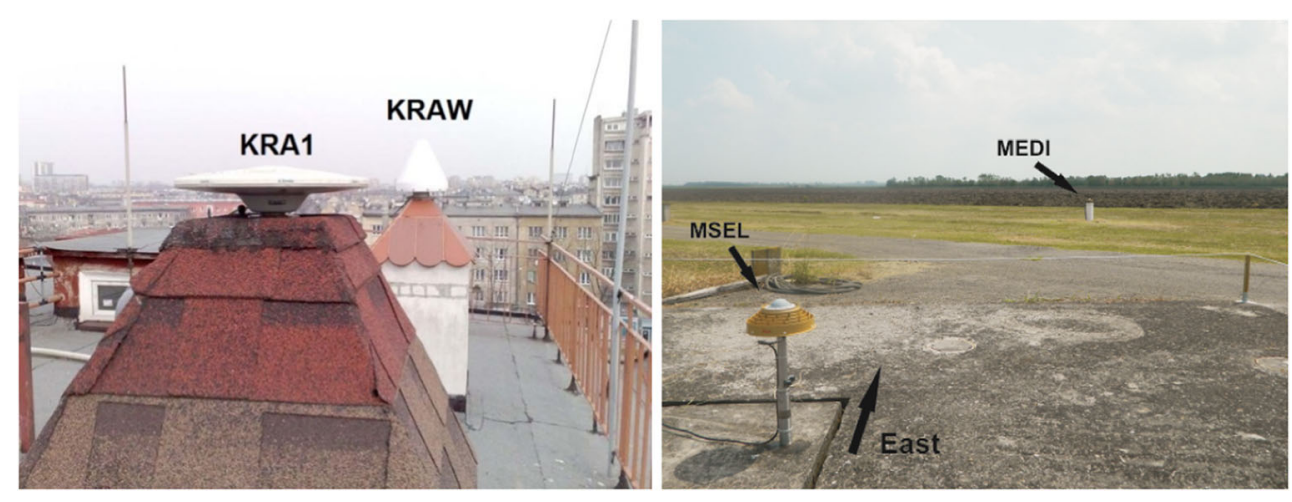
Acknowledgments This paper is made within scientific research 11.11.150.444.

Open Access This article is distributed under the terms of the Creative Commons Attribution 4.0 International License (http:// creativecommons.org/licenses/by/4.0/), which permits unrestricted use, distribution, and reproduction in any medium, provided you give appropriate credit to the original author(s) and the source, provide a link to the Creative Commons license, and indicate if changes were made.

\section{References}

Alinia HS, Tiampo KF, James TS (2017) GPS coordinate time series measurements in Ontario and Quebec, Canada. J Geod 91:653683. https://doi.org/10.1007/s00190-016-0987-5

Araszkiewicz A, Völksen C (2016) The impact of the antenna phase center models on the coordinates in the EUREF Permanent Network. GPS Solutions 21:1-11. https://doi.org/10.1007/s10291016-0564-7

Araszkiewicz A, Bogusz J, Figurski M (2009) Investigation on tidal components in GPS coordinates. Artificial Satellites 44:67-74. https:// doi.org/10.2478/v10018-009-0020-9

Araszkiewicz A, Bogusz J, Figurski M et al (2010) Centre of Applied Geomatics activities in the context of the EUREF project. Reports on Geodesy 1:89-96

Bellone T, Dabove P, Manzino AM, Taglioretti C (2016) Real-time monitoring for fast deformations using GNSS low-cost receivers. Geomat Nat Haz Risk 7:458-470. https://doi.org/10.1080/ 19475705.2014.966867

Bhu H, Purohit R, Ram J et al (2014) Neotectonic activity and parity in movements of Udaipur block of the Arvalli Craton and Indian Plate. J Earth Syst Sci 123:343-350. https://doi.org/10.1007/s12040-014-0405-4

Bogusz J, Figurski M (2012) GPS-derived height changes in diurnal and sub-diurnal timescales. Acta Geophys 60:295-317. https://doi.org/ 10.2478/s11600-011-0074-5

Bogusz J, Figurski M (2014) Annual signals observed in regional GPS networks. Acta Geodyn Geomater 11:1-7. https://doi.org/10.13168/ AGG.2014.0003

Bogusz J, Klos A (2016) On the significance of periodic signals in noise analysis of GPS station coordinates time series. GPS Solutions 20: 655-664. https://doi.org/10.1007/s10291-015-0478-9

Bogusz J, Figurski M, Kroszczyński K, Szafranek K (2011) Investigation of environmental influences to the precise GNSS solutions. Acta Geodyn Geomater 8:5-15

Bruyninx C (2000) Review of the coordination tasks within the EUREF Permanent GPS Network (EPN). In: XXIII ${ }^{\text {rd }}$ Meeting of the EUREF TWG in Tromsø. pp 381-382

Bruyninx C, Carpentier G, Defraigne P (2005) Analysis of the coordinate differences caused by different methods to align the combined EUREF solution to the ITRF. EUREF Symp 1-8

Bruyninx C, Habrich H, Söhne W et al (2012) Enhancement of the EUREF permanent network services and products. pp 27-34

Calais E, Han JY, DeMets C, Nocquet JM (2006) Deformation of the North American plate interior from a decade of continuous GPS measurements. J Geophys Res 111:B06402. https://doi.org/10. 1029/2005JB004253

Caliro S, Chiodini G, Galluzzo D et al (2004) Recent activity of Nisyros volcano (Greece) inferred from structural, geochemical and seismological data. Bull Volcanol 67:358-369. https://doi.org/10.1007/ s00445-004-0381-7

Capilla RM, Berné JL, Martín A, Rodrigo R (2016) Simulation case study of deformations and landslides using real-time GNSS precise point positioning technique. Geomatics, Nat Hazards Risk 7:1856-1873. https://doi.org/10.1080/19475705.2015.1137243

Cho I, Kuwahara Y (2013) Numerical simulation of crustal deformation using a three-dimensional viscoelastic crustal structure model for the Japanese islands under east-west compression. Earth Planets Space 65:1041-1046. https://doi.org/10.5047/eps.2013.05.006

Collilieux X, Métivier L, Altamimi Z et al (2011) Quality assessment of GPS reprocessed terrestrial reference frame. GPS Solutions 15:219 231. https://doi.org/10.1007/s10291-010-0184-6

Dong D, Fang P, Bock Y et al (2002) Anatomy of apparent seasonal variations from GPS-derived site position time series. J Geophys Res 107:ETG 9-1-ETG 9-16. https://doi.org/10.1029/ 2001JB000573

EPNCG (2016) Guidelines for the EPN Analysis Centres

Hammond WC (2005) Northwest Basin and Range tectonic deformation observed with the global positioning system, 1999-2003. J Geophys Res 110:B10405. https://doi.org/10.1029/2005JB003678

Hefty J, Igondová M, Hrcka M (2005) Contribution of GPS permanent stations in Central Europe to regional geo-kinematical investigations. Acta Geodyn Geomater 2:75-86

Hefty J, Igondová M, Droščák B (2009) Homogenization of long-term GPS monitoring series at permanent stations in Central Europe and Balkan Peninsula. Contributions to Geophysics and Geodesy 39: 19-42. https://doi.org/10.2478/v10126-009-0002-8

Kadirov FA, Guliyev IS, Feyzullayev AA et al (2014) GPS based crustal deformations in Azerbaijan and their influence on seismicity and mud volcanism. Izv Phys Solid Earth 50:814-823. https://doi.org/ 10.1134/S1069351314060020

Kenyeres A, Bruyninx C (2004) EPN coordinate time series monitoring for reference frame maintenance. GPS Solutions 8:200-209. https:// doi.org/10.1007/s10291-004-0104-8

Komac M, Holley R, Mahapatra P et al (2015) Coupling of GPS/GNSS and radar interferometric data for a 3D surface displacement monitoring of landslides. Landslides 12:241-257. https://doi.org/10. 1007/s10346-014-0482-0

Kulachi F (2000) Indian plate kinematic studies by GPS-geodesy. Earth Planets Space 52:741-745

Levin VE, Bakhtiarov VF, Pavlov VM et al (2010) Geodynamic studies of the April 20(21), 2006 Olyutorskii earthquake based on observations by the Kamchatka GPS network. J Volcanol Seismol 4:193202. https://doi.org/10.1134/S0742046310030048

Liu B, Dai W, Peng W, Meng X (2015) Spatiotemporal analysis of GPS time series in vertical direction using independent component analysis. Earth Planets Space 67:189. https://doi.org/10.1186/s40623-015-0357-1

MathWorks (2004) Curve fitting toolbox user's guide. 1-657

Medvedev IP, Rabinovich AB, Kulikov EA (2013) Tidal oscillations in the Baltic Sea. Oceanology 53:526-538. https://doi.org/10.1134/ S0001437013050123

Miller V, Hurst T, Beavan J (2003) Feasibility study for geodetic monitoring of Mt Ruapehu volcano, New Zealand, using GPS. N Z J Geol Geophys 46:41-46. https://doi.org/10.1080/00288306.2003.9514994

Milyukov V, Mironov A, Rogozhin EA, Steblov GM (2015) Velocities of contemporary movements of the Northern Caucasus estimated from GPS observations. Geotectonics 49:210-218. https://doi.org/10. $1134 / \mathrm{S} 0016852115030036$

Park KD, Won J (2010) The foliage effect on the height time series from permanent GPS stations. Earth Planets Space 62:849-856. https:// doi.org/10.5047/eps.2010.10.005

Pospíśil L, Hefty J, Hipmanová L (2012) Risk and geodynamically active areas of the carpathian lithosphere on the base of geodetical and geophysical data. Acta Geodaetica et Geophysica Hungarica 47: 287-309. https://doi.org/10.1556/AGeod.47.2012.3.2

Priego E, Jones J, Porres MJ, Seco A (2016) Monitoring water vapour with GNSS during a heavy rainfall event in the Spanish Mediterranean area. Geomat Nat Haz Risk 5705:1-13. https://doi.org/10.1080/ 19475705.2016.1201150 
Ray J, Altamimi Z, Collilieux X, van Dam T (2008) Anomalous harmonics in the spectra of GPS position estimates. GPS Solutions 12:55-64. https://doi.org/10.1007/s10291-007-0067-7

Rogozhin EA (2011) March 11, 2011 M 9.0 Tohoku earthquake in Japan: tectonic setting of source, macroseismic, seismological, and geodynamic manifestations. Geotectonics 45:337-348. https://doi. org/10.1134/S0016852111050025

Steigenberger P, Rothacher M, Dietrich R et al (2006) Reprocessing of a global GPS network. J Geophys Res Solid Earth 111:1-13. https:// doi.org/10.1029/2005JB003747

Tan S (2018) GNSS systems and engineering: the Chinese Beidou navigation and position location satellite

Tanaka T, Nakano T, Hoso Y et al (1998) Comparison of crustal deformations observed with GPS and strainmeters/tiltmeters. In: Geodesy on the Move, pp 450-458

Teferle F, Orliac EJ, Bingley R (2007) An assessment of Bernese GPS software precise point positioning using IGS final products for global site velocities. GPS Solutions 11:205-213. https://doi.org/10. 1007/s10291-006-0051-7

Trofimenko SV, Bykov VG (2014) Model of crustal block movement in the South Yakutia geodynamic testing area based on GPS data.
Russian Journal of Pacific Geology 8:247-255. https://doi.org/10. 1134/S1819714014040071

Uzel T, Eren K, Gulal E et al (2013) Monitoring the tectonic plate movements in Turkey based on the national continuous GNSS network. Arab J Geosci 6:3573-3580. https://doi.org/10.1007/s12517-012-0631-5

Wang G, Kearns TJ, Yu J, Saenz G (2014) A stable reference frame for landslide monitoring using GPS in the Puerto Rico and Virgin Islands region. Landslides 11:119-129. https://doi.org/10.1007/ s10346-013-0428-y

Wang G, Bao Y, Cuddus Y et al (2015) A methodology to derive precise landslide displacement time series from continuous GPS observations in tectonically active and cold regions: a case study in Alaska. Nat Hazards 77:1939-1961. https://doi.org/10.1007/s11069-015-1684-z

Zhang F, Dong D, Cheng Z et al (2002) Seasonal vertical crustal motions in China detected by GPS. Chin Sci Bull 47:1772-1779. https://doi. org/10.1360/02tb9387

Zhang J, Ren J, Chen C et al (2014) The Late Pleistocene activity of the eastern part of east Kunlun fault zone and its tectonic significance. Sci China Earth Sci 57:439-453. https://doi.org/10.1007/s11430013-4759-2 